\title{
PENGARUH GUNCANGAN OUTPUT GAP DAN INFLASI TERHADAP SUKU BUNGA SEBAGAI SASARAN OPERASIONAL KEBIJAKAN MONETER DI INDONESIA
}

\author{
Utami Baroroh \\ UIN Syarif Hidayatullah Jakarta \\ utami.baroroh@uinjkt.ac.id
}

\begin{abstract}
The objectives of this study are to observe interest rate response because shock/innovation of inflation and output gap. The data sample used in this study are quarterly time series data from 1983.1 - 2008.4. Those data are SBI interest rate, inflation (CPI) and output gap. A method of analysis in this study is Vector Error Correction Model (VECM). The empirical results of impulse response show that the effect of inflation and output gap shock to interest rate is positif.
\end{abstract}

Keywords: Inflation; Output Gap; Interest Rate

\begin{abstract}
Abstrak
Tujuan dari penelitian ini adalah untuk mengamati respons suku bunga karena syok / inovasi inflasi dan output gap. Sampel data yang digunakan dalam penelitian ini adalah kuartalan data time series 1.983,1-2.008,4. Data mereka adalah tingkat suku bunga SBI, inflasi (CPI) dan output gap. Sebuah metode analisis dalam penelitian ini adalah Vector Error Correction Model (VECM). Hasil empiris dari respon impuls menunjukkan bahwa efek dari inflasi dan output gap shock suku bunga adalah positif. Kata Kunci: Inflasi; Gap Keluaran; Suku Bunga
\end{abstract}




\section{PENDAHULUAN}

Dalam literatur ekonomi, peran kebijakan moneter dalam stabilisasi perekonomian telah lama menjadi perdebatan diantara ekonom. Perdebatan ini dapat dilihat dari diskusi antara Keynesian yang menekankan pentingnya peran kebijakan fiskal dibandingkan dengan moneter. Sedangkan Friedman and Schwartz berpendapat bahwa terjadinya Great Depression di Amerika Serikat membuktikan peran uang bagi perekonomian. Kegagalan Federal Reserve sebagai Bank Sentral dalam mencegah jatuhnya sistem perbankan, telah menyebabkan menurunnya jumlah uang yang beredar dari akhir tahun 1930 sampai 1933.

Bank sentral sebagai pembuat kebijakan moneter harus memperhatikan bahwa setiap keputusan yang ditetapkan dapat mempengaruhi pergerakan output, suku bunga, harga dan variabel makro lainnya. Hal ini merefleksikan adanya trade-off dalam siklus stabilitas ekonomi, dan menjaga stabilitas harga (inflasi) sebagai sasaran akhir kebijakan moneter adalah target yang telah ditetapkannya. Namun, sasaran tersebut secara bersamaan seringkali bersifat kontradiktif. Sejak tahun 1983 kebijakan moneter di Indonesia dilakukan terutama melalui pengendalian jumlah uang beredar, yaitu dengan mengupayakan agar likuiditas perekonomian tersedia dalam jumlah yang cukup untuk mendukung pencapaian tingkat pertumbuhan ekonomi yang diinginkan. Kebijakan moneter melalui pengendalian jumlah uang beredar yang selama ini dilakukan di Indonesia menunjukkan kinerja yang cenderung menurun. Hal ini dapat dilihat dari target yang tidak pernah tercapai sesuai dengan yang ditetapkan oleh Bank Indonesia (Warjiyo dan Zulverdi, 1998).

Fenomena tersebut mendorong perlu dilakukannya upaya membuat model yang menggunakan suku bunga sebagai salah satu instrumen kebijakan moneter. Perubahan (shock) suku bunga sebagai instrumen kebijakan moneter dapat mempengaruhi variabel makroekonomi lainnya, sebaliknya perubahan kondisi makro seperti tingkat inflasi atau tingkat aktifitas ekonomi menyebabkan perubahan target operasional bank sentral untuk mengontrol tingkat suku bunga. 
Paul dan Vredin (2003) melakukan penelitian yang mengkaji kemampuan prediksi dari suku bunga model Taylor Rule. Hasil penelitian mereka menunjukkan besarnya prediksi perubahan tingkat suku bunga dipengaruhi oleh kenaikan prediksi output gap dan inflasi. Dalam kasus ini, suku bunga mengalami perubahan dikarenakan adanya shock kebijakan dan penetapan target suku bunga kedepan. Implikasinya kebijakan dari penelitian Paul dan Vredin bahwa perkiraan perubahan suku bunga setara dengan perkiraan akan perbedaan antara target suku bunga dan lag suku bunga (dalam hal ini disebut gap target).

Sebagai upaya untuk mendorong perekonomian melalui pengaturan suku bunga yang akan berdampak pada kegiatan investasi dan tabungan di Indonesia, maka pada penelitian ini akan mengkaji kekuatan variabel-variabel endogen dalam merespon adanya shock instrumen kebijakan moneter dan variabel lainnya hingga terwujudnya sasaran akhir kebijakan moneter.

Secara umum strategi bank sentral dalam melakukan kebijakan moneternya untuk mencapai tujuan akhirnya adalah sebagai berikut (Mishkin, 2009):

Tabel 1. Strategi Bank Sentral

\begin{tabular}{cclc}
\hline $\begin{array}{c}\text { Alat } \\
\text { (Tools) }\end{array}$ & $\begin{array}{c}\text { Sasaran Operasi } \\
\text { (Operating Targets) }\end{array}$ & $\begin{array}{c}\text { Sasaran Antara } \\
\text { (Intermediate Targets) }\end{array}$ & \multicolumn{2}{c}{ Tujuan } \\
- Goals)
\end{tabular}

Sumber: Mishkin, 2009

Dari skema di atas, bank sentral dalam melakukan kebijakan moneternya menggunakan instrumen yang meliputi operasi pasar terbuka (misalnya SBI kalau di Indonesia), kebijakan diskonto, dan cadangan wajib minimum. Instrumen-instrumen tersebut digunakan untuk mencapai sasaran operasional (operating targets). Sasaran yang dimaksud adalah reserve aggregate, yang meliputi total reserves pada bank sentral atau uang primer dan monetary base, serta suku bunga jangka pendek, yang selanjutnya 
digunakan untuk mencapai sasaran menengah atau antara (intermediate targets). Sasaran menengah yang dimaksud adalah monetery aggregates (M1, M2, M3) dan suku bunga baik jangka pendek maupun jangka panjang, yang selanjutnya digunakan untuk mencapai tujuan akhir, yaitu kesempatan kerja yang tinggi, stabilitas harga atau inflasi, stabilitas pasar keuangan, dan lainnya.

Pada penelitian ini, ada dua faktor yang merespon suku bunga yaitu inflasi dan output gap. Suku bunga yang dimaksud dalam model ini adalah suku bunga jangka pendek, untuk Indonesia suku bunga dalam penelitian ini menggunakan suku bunga yang diamati dari suku bunga SBI. Dalam kaitannya antara tingkat inflasi (IHK) dan Output gap (PDB) yang memberi respon pada suku bunga akan dijelaskan pada sub bab di bawah ini.

Beberapa model teori diperkenalkan dalam mengembangkan kebijakan suku bunga untuk mengkontrol inflasi. Salah satu kebijakannya yaitu dengan menerapkan Taylor rule yang mengatur suku bunga yang dilakukan oleh bank sentral. Model Taylor Rule diperoleh dari kombinasi IS-Curve (hubungan suku bunga nominal dengan harapan inflasi) dengan Philips curve yang berkaitan dengan inflasi. Berkaitan dengan tingkat bunga nominal dan tingkat bunga riil yang menetapkan bahwa tingkat bunga nominal $i$ sama dengan tingkat bunga riil $r$ ditambah dengan inflasi yang diharapkan $\pi^{e}$ (Mishkin, 2009).

$$
\mathrm{i}=\mathrm{i}_{\mathrm{r}}+\mathrm{m}^{\mathrm{e}}
$$

dimana: $\mathrm{i}$ adalah tingkat bunga nominal, $\mathrm{i}_{\mathrm{r}}$ adalah tingkat bunga riil dan $\pi^{\mathrm{e}}$ adalah inflasi yang diharapkan.

Apabila inflasi yang diharapkan meningkat, kurva penawaran bergeser dari $\mathrm{B}^{\mathrm{S}}{ }_{1}$ ke $\mathrm{B}^{\mathrm{S}}{ }_{2}$ dan kurva permintaan bergeser dari $\mathrm{B}^{\mathrm{D}}{ }_{1}$ ke $\mathrm{B}^{\mathrm{D}}{ }_{2}$, maka keseimbangan berpindah dari titik 1 ke titik 2 dengan harga bond turun dari $\mathrm{P}_{1}$ ke $P_{2}$ dan keseimbangan tingkat bunga meningkat dari $i_{1} k_{1} i_{2}$. Jadi, jika inflasi yang diharapkan meningkat, tingkat bunga akan meningkat, yang lebih dikenal dengan Fisher Effect (Mishkin, 2009).

Dalam mekanisme transmisi moneter, di Indonesia dikenal beberapa jenis suku bunga jangka pendek yaitu suku bunga SBI (sertifikat Bank Indonesia), suku bunga SBPU (Surat Berharga Pasar Uang), suku bunga 
PUAB (Pasar Uang Antar Bank), suku bunga kredit modal kerja, suku bunga kredit investasi, dan deposito berjangka 1 bulan sampai 2 tahun.

Warjiyo dan Zulverdi (1998) dalam studinya menganalisis hubungan antara suku bunga dan inflasi dengan menerapkan uji kausalitas Granger. Berdasarkan hasil analisis tersebut, suku bunga deposito 1 bulanan dan suku bunga KMK (Kredit Modal Kerja) memiliki hubungan cukup kuat terhadap inflasi. Sementara suku bunga deposito berjangka 3 bulanan, 6 bulanan dan 12 bulanan tidak mempunyai hubungan. Mekanisme transmisi yang diusulkan dalam penelitian ini adalah berdasarkan operasi pasar terbuka melalui aktivitas jual beli SBI/SBPU. Perubahan suku bunga kedua surat berharga ini ditransmisikan ke dalam suku bunga PUAB (Pasar Uang Antar Bank) yang selanjutnya diteruskan ke suku bunga deposito. Suku bunga deposito akan ditransmisikan ke sektor riil melalui output nasional (PDB). Mekanisme penjelasan sebagai berikut:

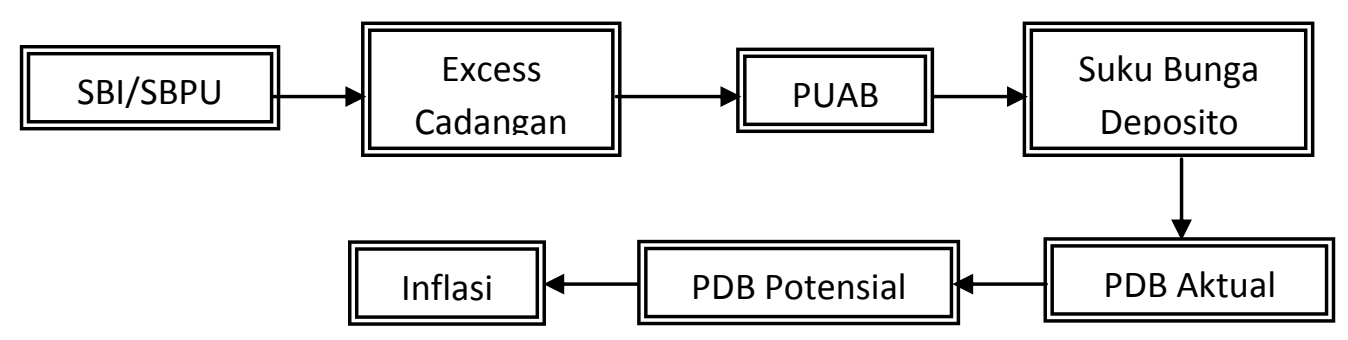

Gambar 1. Skema Mekanisme Hubungan Pengaruh SBI Terhadap Inflasi

Pada saat menggunakan kebijakan SBI (sertifikat Bank Indonesia), misalnya kenaikan SBI, maka suku bunga jangka pendek dipasar uang akan segera merespon secara positif. Demikian juga halnya dengan suku bunga jangka panjang, produsen akan merespon kenaikan suku bunga di pasar uang dengan mengurangi investasinya, maka produksi dalam negeri (output) menurun sehingga tingkat inflasi domestik menurun.

Dalam perekonomian inflasi dapat terjadi dari sisi permintaan (demand full inflation) dan sisi penawaran (cost push inflation). Dari sisi permintaan, biasanya digunakan persamaan kuantitatif sebagai salah satu teori inflasi 
untuk menggantikan total output (PDB) dengan jumlah transaksi $(T)$ dalam perekonomian. Transaksi dan output sangat berkaitan, karena semakin banyak perekonomian berproduksi akan semakin banyak barang akan dibeli dan dijual (Mankiw, 2009).

Output gap adalah selisih antara sisi demand yang diwakili oleh output aktual (PDB) dan dari sisi supply yang diwakili oleh output potensial (PDB Potensial). Jika PDB aktual > PDB potensial, maka output gap bernilai positif. Demikian sebaliknya jika PDB aktual < PDB Potensial, maka output gap bernilai negatif. Pada saat output gap bernilai negatif, hal ini menunjukkan bahwa tingkat inflasi kemungkinan besar akan turun, bahkan ketika output gap positif kemungkinan akan mendorong inflasi meningkat. Hal ini sering terjadi diakhir periode pertumbuhan ekonomi yang berkesinambungan dalam jangka waktu yang panjang.

Penjelasan Friedman dalam teori yang mengkaitkan hubungan antara output yang memberi respon pada perubahan suku bunga dikenal dengan efek likuiditas. Penurunan tingkat suku bunga akan diikuti oleh naiknya jumlah investasi, sehingga akan berdampak pada naiknya pendapatan (income). Sebetulnya dalam analisis liquidity effect dapat dijelaskan bahwa adanya kenaikan tingkat suku bunga akan membuat naiknya pendapatan nominal sebagai akibat naiknya output. Dengan naiknya tingkat pendapatan (income), maka akan mengakibatkan naiknya jumlah permintaan dana yang dapat dipinjam.

\section{METODE}

Penelitian ini menggunakan data runtut waktu (time series) dengan data kuartalan dari tahun 1983 - 2008. Data yang digunakan meliputi kesenjangan output (output gap), inflasi dan tingkat suku bunga SBI 3 bulan. Data output gap diperoleh dengan cara menghitung persentase perbedaan antara output dari sisi permintaan agregat (AD) dengan output potensial dari sisi penawaran agregat (AS). Data inflasi yang digunakan dalam penelitian ini adalah inflasi dari Indeks Harga Konsumen (IHK). Data estimasi output gap diperoleh dengan Hodrick-Prescott Filter (HP Filter) yaitu metode smoothing sederhana 
yang dapat digunakan untuk mendapatkan tren output dan pergerakan fluktuasinya.

Data dalam penelitian ini diambil dari berbagai sumber seperti laporan tahunan $\mathrm{BI}$, laporan $\mathrm{BI}$, Statistik Ekonomi dan Keuangan Indonesia (SEKI), situs BI, situs BPS, dan CD-rom Internasional Financial Statistics (IFS). Penelitian ini akan mengolah dan menganalisis data dengan menggunakan alat analisis vector error correction model (VECM). Melalui model VECM ini dapat diketahui perilaku kointegrasi jangka panjang variabel yang diamati, maupun dinamika variabel tersebut dalam jangka pendek. Terminologi kointegrasi mengacu pada error correction term (ECT), karena penyimpangan variabel tersebut dalam jangka pendek dari keseimbangan jangka panjangnya yang secara bertahap dikoreksi melalui proses penyesuaian jangka pendek.

Dengan sistem persamaan yang terdiri dari dua variabel dan satu persamaan kointegrasi, maka bentuk persamaan kointegrasi dimisalkan sebagai berikut:

$$
Y_{2, t}=\beta y_{1, t}
$$

Persamaan VECM dinyatakan dengan persamaan berikut:

$$
\begin{aligned}
& \Delta \mathrm{y}_{1 \mathrm{t}}=\alpha_{1}+\sum_{\mathrm{j}=1}^{2} \beta_{\mathrm{j}} \Delta \mathrm{y}_{1, t-\mathrm{j}}+\sum_{\mathrm{j}=1}^{2} \xi_{\mathrm{j}} \Delta \mathrm{y}_{2, t-\mathrm{j}}+\gamma_{1}\left(\mathrm{y}_{2, t-1}-\varphi \mathrm{y}_{1, t-1}\right)+\mu_{\mathrm{tt}} \\
& \Delta \mathrm{y}_{2 \mathrm{t}}=\alpha_{2}+\sum_{\mathrm{j}=1}^{2} \theta_{\mathrm{j}} \Delta \mathrm{y}_{1, t-\mathrm{j}}+\sum_{\mathrm{j}=1}^{2} \lambda_{\mathrm{j}} \Delta \mathrm{y}_{2, t-\mathrm{j}}+\gamma_{2}\left(\mathrm{y}_{2, t-1}-\varphi \mathrm{y}_{1, t-1}\right)+\mu_{2 t}
\end{aligned}
$$

Dimana $\left(y_{2, t-1}-\varphi y_{1, t-1}\right)$ adalah error correction term (ECT).

Dalam jangka panjang ECT sama dengan nol. Jika $y_{1, t}$ dan $y_{2, t}$ terdeviasi dari keseimbangan jangka penjang periode sebelumnya, maka ECT tidak sama dengan nol, dan masing-masing variabel akan menyesuaikan kembali menuju keseimbangan jangka panjangnya dengan kecepatan penyesuaian (speed of adjustment) ditunjukkan dengan koefisien $\mathrm{y}_{1}$ dan $\mathrm{\gamma}_{2}$.

Fungsi impulse response dan variance decomposition merupakan properti dari model VECM/VAR untuk melihat dampak goncangan dari variabel inovasi terhadap variabel-variabel lainnya. Impulse response adalah respon variabel endogen akibat adanya inovasi (kejutan) dari variabel endogen yang lain. Dengan menggunakan analisis impulse response dapat 
disimulasikan dampak perubahan salah satu variabel independen terhadap fluktuasi variabel dependennya pada masa yang akan datang. Variance decomposition bertujuan untuk memisahkan dampak masing-masing variabel inovasi tersebut secara individual terhadap respon yang diterima suatu variabel.

Analisis impulse response mempunyai kemampuan forward looking sehingga berguna untuk melacak atau memprediksi nilai sekarang dan yang akan datang dari variabel endogen akibat adanya efek kejutan atau inovasi atas variabel yang bersangkutan. Impulse response merupakan suatu alur (path) dimana variabel akan kembali pada keseimbangan setelah mengalami kejutan. Bentuk reduce form dari representasi moving average dapat ditulis sebagai berikut :

$$
\Delta x_{\mathrm{t}}=\varepsilon_{\mathrm{t}}+\Sigma \psi_{\mathrm{m}} \varepsilon_{\mathrm{t}-\mathrm{m}}
$$

Maka koefisien $\psi_{m}$ dapat diinterpretasikan sebagai respon lag ke-m dari setiap unit kenaikan yang terjadi pada periode $t$, atau:

$$
\psi_{\mathrm{m}}=\frac{\delta\left(\Delta \mathrm{x}_{\mathrm{t}+\mathrm{m}}\right)}{\delta \varepsilon_{\mathrm{t}}}
$$

Respon lag atas terjadinya satu kejutan (inovasi) pada gangguan $\left(\varepsilon_{\mathrm{t}}\right)$ secara orthogonal dinyatakan:

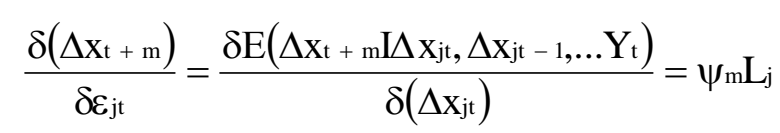

Di mana $L_{j}$ adalah kolom j dari matrik triangular $L$ dan $Y_{t}=\left[\Delta x_{t-1}, \ldots, \Delta x_{t-p}\right]$. Persamaan tersebut dikenal dengan fungsi impulse response.

Sedangkan analisis variance decomposition adalah mendekomposisi variasi kesalahan prediksi atau menyatakan suatu proporsi dari rangkaian perubahan dikarenakan adanya kejutan atas variabel satu terhadap kejutan variabel yang lain. Secara matematis nilai variance decomposition dapat dinyatakan sebagai berikut. MSE dari langkah prediksi ke-m dapat dihitung sebagai:

$\mathrm{E}\left(\Delta \mathrm{x}_{\mathrm{t}+\mathrm{m}}-\Delta \mathrm{x}_{\mathrm{t}+\mathrm{m} \mid \mathrm{t}}\right)\left(\Delta \mathrm{x}_{\mathrm{t}+\mathrm{m}}-\Delta \mathrm{x}_{\mathrm{t}+\mathrm{m} \mid \mathrm{t}}\right)=\Sigma+\psi_{1} \Sigma \psi_{\mathrm{i}}+\ldots+\psi_{\mathrm{m}-1} \Sigma \psi_{\mathrm{m}-1}^{\prime}$

Dengan catatan bahwa $\varepsilon_{\mathrm{t}}=L e_{\mathrm{t}}$. Kemudian matrik covariance $\varepsilon_{\mathrm{t}}$ apabila didekomposisi: 


$$
\Sigma=\Sigma L_{i} L^{\prime} d_{i i}
$$

di mana $\mathrm{d}_{\mathrm{ii}}$ adalah elemen diagonal i matrik $\mathrm{D}$ dan $\mathrm{n}$ adalah jumlah variabel Maka matrik MSE dapat ditulis :

$$
\Sigma d_{i i}\left[L_{i} L_{i}^{\prime}+\psi_{1} L_{i} L_{i}^{\prime} \psi^{\prime}{ }_{1}+\ldots+\Psi_{m-1} L_{i} L_{i}^{\prime} \psi_{m-1}^{\prime}\right]
$$

Oleh karena itu, kontribusi inovasi atau kejutan orthogonal $i$ terhadap MSE

$$
V t=d_{i i}\left[L_{i} L_{i}^{\prime}+\Psi_{1} L_{i} L_{i}^{\prime} \psi_{1}^{\prime}+\ldots+\Psi_{m-1} L_{i} L_{i}^{\prime} \psi_{m-1}^{\prime}\right]
$$

Jadi, dekomposisi variasi kesalahan prediksi ke-i atau variance decomposition ke-i diperoleh dari elemen diagonal matrik $V_{t}$.

Sebelum mengaplikasikan dan menganalisis model VECM; perlu ditentukan panjang lag. Ada beberapa cara untuk menentukan panjang lag, namun cara termudah adalah melakukan iterasi yang dimulai dari lag terpanjang, kemudian membandingkan nilai Akaike AIC dan Schwarz SC. Lag optimal jika memiliki nilai Akaike AIC dan Schwarz SC yang terkecil (Gujarati, 2009).

\section{HASIL DAN PEMBAHASAN}

Sebelum melakukan pengujian VECM, data penelitian harus diuji terlebih dahulu stasioneritasnya. Secara kuantitatif uji stasioneritas dapat dilakukan dengan unit root test (uji akar-akar unit). Prosedur pengujian akarakar unit yang biasa digunakan adalah uji DF dan ADF (Dickey Fuller dan Augmented Dickey Fuller Test). Hasil pengujian akar-akar unit dari variabel suku bunga $\mathrm{SBI}(\mathrm{R})$, inflasi (INF) dan output gap (GAP) ditunjukkan pada tabel 1. berikut ini:

Tabel 1. Uji Akar-akar Unit

\begin{tabular}{lll}
\hline Variabel & Level & \\
& DF Stat & ADF Stat \\
\hline $\mathrm{R}$ & $-3,530114$ & $-3,494459$ \\
INF & $-4,340383$ & $-4,354598$ \\
GAP & $-6,566074237$ & $-4,257051$ \\
\hline
\end{tabular}

Sumber: Lampiran 2

Ket: Nilai kritis DF $1 \%:-3,5111$

ADF $1 \%:-4,0727$

$5 \%:-2,8967$

$5 \%:-3,4645$

$10 \%:-2,5853$

$10 \%:-3,1585$ 
Berdasarkan tampilan yang disajikan pada tabel 1 , secara umum variabel-variabel dalam model dapat dikatakan stasioner pada level atau I(0). Bila data yang diamati pada uji akar-akar unit ternyata tidak stasioner, maka langkah selanjutnya melakukan uji derajat integrasi. Uji ini dilakukan terhadap derivasi ke-n dari data yang akan diuji dengan tujuan untuk mengetahui pada derajat berapa data yang diamati akan stasioner. Definisi formal dari integrasi suatu data adalah suatu data runtun waktu dikatakan berintegrasi pada derajat $d$ atau $\mathrm{I}(\mathrm{d})$, bila data tersebut memerlukan differencing sebanyak $\mathrm{d}$ kali agar didapat data yang stasioner (Insukindro, 1992: 262).

Uji kointegrasi ini merupakan kelanjutan dari uji akar-akar unit dan uji derajat integrasi. Uji kointegrasi adalah untuk menguji apakah residual regresi yang dihasilkan stasioner atau tidak. Untuk itu uji kointegrasi harus diyakini terlebih dahulu bahwa variabel yang diamati memiliki derajat integrasi yang sama. Pada umumnya sebagian uji kointegrasi berada pada derajat I (0) atau I (1). Terdapat tiga uji yang umum untuk menguji hipotesis nol tidak adanya kointegrasi, yaitu uji CRDW (Cointegrating Regression Durbin Watson), DF (Dickey-Fuller), dan ADF (Augmented Dickey-Fuller)(Engle dan Granger, 1987).

Tabel 2. Uji Kointegrasi

\begin{tabular}{crr}
\hline $\begin{array}{c}\text { Variabel } \\
\text { Nilai Koef. }\end{array}$ & \multicolumn{2}{c}{ T-Stat } \\
\hline Konstanta & 13,0215 & 17,4573 \\
INF & 0,7817 & 4,4925 \\
GAP & 0,2378 & 1,8132 \\
CRDW & 0,6985 & \\
\hline DF & $-4,0508$ \\
ADF & $-3,6648$ & \\
\hline \multicolumn{4}{c}{ Sumber: data diolah $\alpha=5 \% \quad \alpha=10 \%$} \\
Ket: CRDW : 0,78 & $: 0,69$ \\
& DF : 4,11 & $: 3,73$ \\
& ADF : 3,75 & $: 3,36$
\end{tabular}


Untuk menghitung statistik CRDW, DF dan ADF ditaksir regresi kointegrasi dengan OLS. Setelah residual " $e$ " diketahui maka dilakukan penaksiran model otoregresif dari residual tersebut dengan persamaan OLS. Setelah residual "e" diketahui maka dilakukan penaksiran model otoregresif dari residual tersebut dengan persamaan OLS. Kriteria pengujiannya adalah jika nilai DF (ADF) hitung lebih besar dari nilai kritisnya, maka dapat dikatakan bahwa variabel-variabel pada model yang dibentuk berintegrasi atau residual stasioner. Hasil uji kointegrasi dari variabel suku bunga SBI (R), inflasi (INF) dan output gap (GAP) ditunjukkan pada Tabel 2. Pada Tabel 2 dapat dilihat hasil pengujian kointegrasi dengan menggunakan Engle Granger test. Berdasarkan tampilan diatas, pada persamaan kointegrasi model Taylor rule, residual persamaan tersebut dengan $\alpha=5 \%$ tidak stasioner pada derajat nol tetapi dengan $\alpha=10 \%$ persamaan tersebut telah stasioner pada derajat nol. Berdasarkan hasil estimasi kointegrasi dapat diuraikan bahwa dalam jangka panjang, semua variabel yang mempengaruhi suku bunga di indonesia dalam model Taylor rule mempunyai hubungan keseimbangan jangka panjang yang signifikan secara statistik dengan tanda koefisien sesuai yang diharapkan oleh teori yang terkait.

Setelah dilakukan uji stasioneritas dan kointegrasi, langkah selanjutnya dapat dilakukan estimasi dengan VECM untuk melihat respon suku bunga terhadap guncangan yang terjadi pada inflasi dan output gap atau sebaliknya. Perilaku dinamis dari model VECM dapat dilihat melalui respon dari setiap variabel endogen terhadap kejutan pada variabel tersebut maupun terhadap variabel endogen lainnya. Ada dua cara untuk dapat melihat karakteristik dinamis model VECM, yaitu melalui impulse response dan variance decomposition. Sebelum mengaplikasikan dan menganalisis model VECM, maka perlu ditentukan panjang lag. Lag optimal jika model memiliki nilai Akaike AIC dan Schwarz SC yang terkecil, tetapi metode ini memiliki kelemahan yaitu seringkali terjadi setiap pengurangan lag akan menghasilkan nilai Akaike AIC dan Schwarz SC yang lebih kecil. Adanya kelemahan ini, maka penentuan lag didasarkan pada pendekatan stok yaitu $\mathrm{k}=\mathrm{N}^{1 / 3}$, maka lag yang digunakan pada penelitian ini adalah lag 4 . 
Impulse response adalah respon variabel endogen akibat adanya inovasi (kejutan) dari variabel endogen yang lain. Dengan menggunakan anlisis impulse response dapat disimulasikan dampak perubahan salah satu variabel independen terhadap fluktuasi variabel dependennya pada masa yang akan datang. Seluruh impulse response disajikan pada gambar 1 .

Pesponse to One SD Innovat ons

Pesponse of $\mathrm{R}$ to $\mathrm{R}$

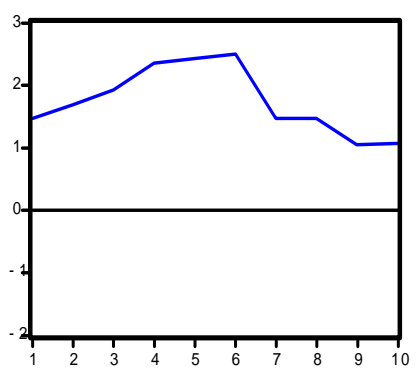

Pesponse of IN to R

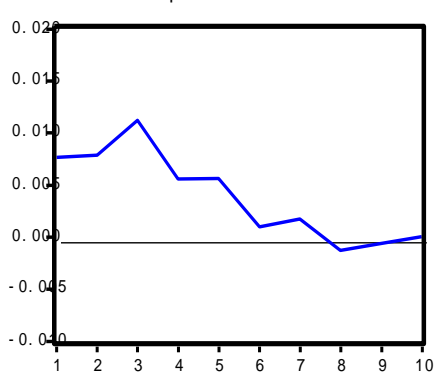

Pesponse of G AP to $R$

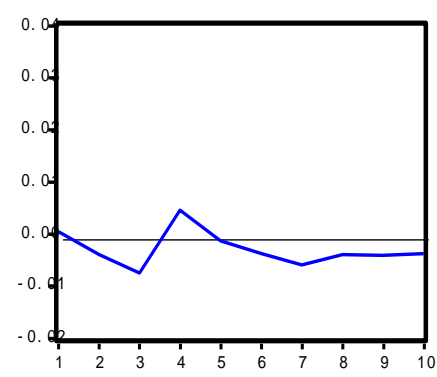

Pesponse of R to INF

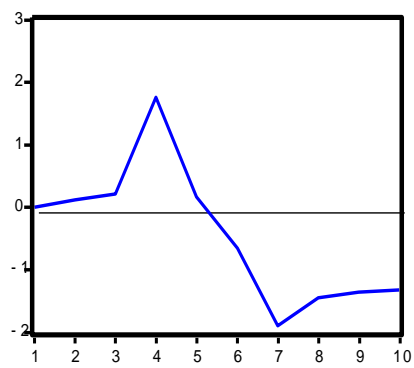

Pesponse of INF to INF

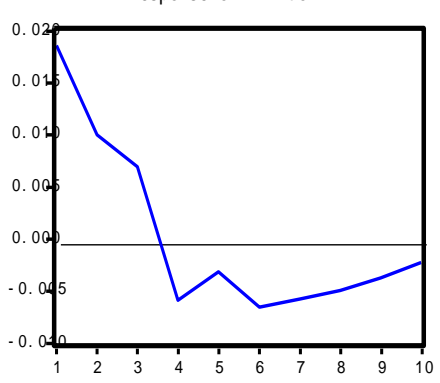

Pesponse of GAP to INF

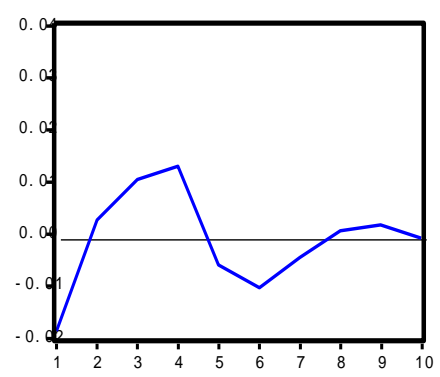

Pesponse of $R$ to $G$ AP

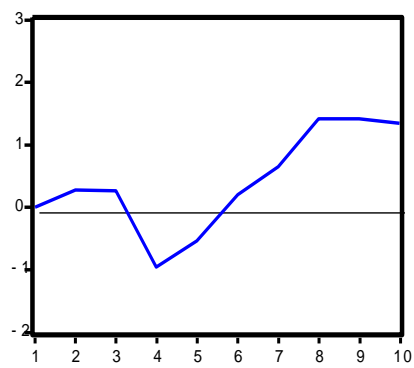

Pesponse of INF to G AP

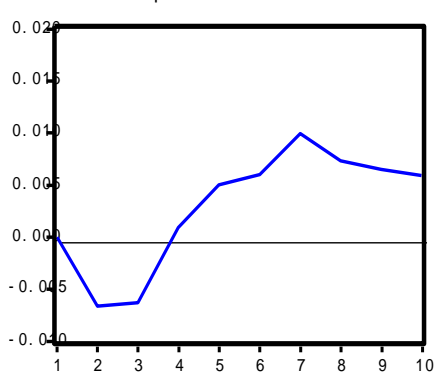

Pesponse of G AP to G AP

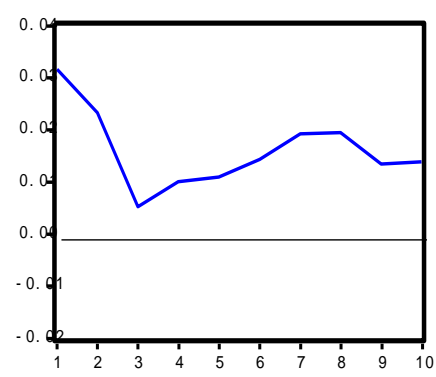

Gambar 1. Impulse Response

Pada Gambar 1 baris pertama menunjukkan respon dari variabel inflasi dan output gap terhadap kejutan satu standar deviasi dari suku bunga. Pada baris pertama terlihat bahwa adanya kejutan atas $R$ awalnya akan meningkatkan $R$ sampai 1,47 dan mencapai puncaknya hingga 2,5 pada periode ke-6. Dampak terhadap $\mathrm{R}$ ini bersifat permanen sehingga $\mathrm{R}$ tidak kembali pada nilainya semula melainkan akan membentuk titik keseimbangan 
yang baru. Pada Gambar 1 baris pertama menunjukkan respon dari variabel inflasi dan output gap terhadap kejutan satu standar deviasi dari suku bunga. Pada baris pertama terlihat bahwa adanya kejutan atas $\mathrm{R}$ awalnya akan meningkatkan $R$ sampai 1,47 dan mencapai puncaknya hingga 2,5 pada periode ke-6. Dampak terhadap $\mathrm{R}$ ini bersifat permanen sehingga $\mathrm{R}$ tidak kembali pada nilainya semula melainkan akan membentuk titik keseimbangan yang baru.

Pada gambar 1 baris pertama menunjukkan respon dari variabel inflasi dan output gap terhadap kejutan satu standar deviasi dari suku bunga. Pada baris pertama terlihat bahwa adanya kejutan atas $\mathrm{R}$ awalnya akan meningkatkan $R$ sampai 1,47 dan mencapai puncaknya hingga 2,5 pada periode ke-6. Dampak terhadap $\mathrm{R}$ ini bersifat permanen sehingga $\mathrm{R}$ tidak kembali pada nilainya semula melainkan akan membentuk titik keseimbangan yang baru. Pada kolom kedua, kejutan INF akan menghasilkan dampak positif terhadap $\mathrm{R}$ hingga periode ke- 5 dan setelah periode ke- 5 dampak tersebut akan menghilang. Pada kolom ketiga menunjukkan adanya kejutan GAP direspon secara positif oleh $\mathrm{R}$, walaupun pada periode ke-4 merespon negatif, tapi kemudian kembali merespon positif, dan adanya kejutan GAP ini akan cenderung membawa $\mathrm{R}$ pada titik keseimbangan baru. Hasil impulse response dapat diringkas pada tabel 4.3.

Tabel 3. Respon Variabel terhadap Kenaikan Satu standar Deviasi dari R Respon R

\begin{tabular}{ll} 
Kejutan R & Positif dan permanen \\
Kejutan INF & Positif dan dampaknya hilang pada kuartal ke-5 \\
Kejutan GAP & Positif dan permanen \\
\hline
\end{tabular}

Analisis ekonomi ini akan menjelaskan bagaimana tingkat suku bunga sebagai salah satu instrumen kebijakan moneter dapat berpengaruh terhadap sasaran akhir yaitu stabilisasi harga (inflasi). Pengendalian tingkat suku bunga sangat penting, karena bila suku bunga terus meningkat akan membawa efek buruk bagi tingkat inflasi serta output riil yang pada akhirnya akan mengganggu ekspor-impor. 
Inflasi yang tinggi dan bergejolak memiliki dampak negatif pada perekonomian secara keseluruhan. Meningkatnya faktor ketidakpastian dalam negeri maupun luar negeri juga berpengaruh terhadap proses pemulihan ekonomi yang mengalami krisis di akhir periode 1998 yang menyebabkan lumpuhnya sektor riil dan dunia usaha di Indonesia.

Tekanan inflasi yang diakibatkan oleh peningkatan output riil merupakan kondisi dimana ketergantungan sektor produksi pada impor bahan baku relatif tinggi. Ketika depresiasi nilai tukar rupiah terhadap dollar AS terjadi, harga input naik sehingga menambah beban peningkatan biaya produksi. Peningkatan ini mengakibatkan efek kenaikan harga yang mendorong terjadi inflasi. Dalam situasi dimana sektor produksi berada di luar jangkauan pengendalian otoritas moneter, maka tekanan inflasi yang bersumber dari noise inflation (agregate supply) hanya bisa teratasi melalui pembenahan sektor riil. Pembenahan sektor riil untuk meningkatkan output dapat dilakukan dengan kebijakan penurunan suku bunga.

Penurunan suku bunga mempunyai tujuan untuk mendorong investasi sektor riil agar terjadi peningkatan output (agregate supply). Peningkatan output tersebut diharapkan akan membawa dampak pada penurunan harga sehingga inflasi dapat dikendalikan pada level tertentu. Selain itu, pengaruh output gap terhadap suku bunga yang tidak terlalu besar tersebut dikarenakan kondisi perekonomian yang belum berada dalam kondisi pengerjaan penuh (under employment) sehingga setiap perubahan dalam komponen output tidak terlalu berdampak banyak terhadap tingkat suku bunga. Dalam jangka panjang, posisi keseimbangan ini akan semakin mendekati kondisi pengerjaan penuh (full employment) dengan kecepatan menuju keseimbangan sebesar $34,64 \%$.

Respon laju pertumbuhan terhadap peningkatan suku bunga SBI adalah negatif. Hal ini mengindikasikan bahwa peningkatan suku bunga SBI juga menaikkan suku bunga di pasar keuangan seperti suku bunga kredit. Kenaikan suku bunga kredit akan menurunkan investasi dan laju pertumbuhan juga menurun. Berdasarkan hasil impulse response dan variance decomposition, terlihat impulse response menunjukkan bahwa 
setelah terjadinya kejutan, maka beberapa saat kemudian (time lag) variabelvariabel tersebut akan kembali pada keseimbangan awal. Apabila kejutan tersebut diasumsikan sebagai tindakan dari otoritas (kebijakan), maka dapat disimpulkan bahwa otoritas mempunyai kemampuan untuk mengendalikan variabel suku bunga tersebut.

\section{SIMPULAN}

Berdasarkan hasil impulse response yang menunjukkan bahwa adanya kejutan (syok) pada inflasi membawa respon yang positif terhadap suku bunga sampai dengan kuartal ke 5 dan akan hilang dampaknya pada kuartal 6. Sedangkan adanya kejutan (syok) pada output gap membawa respon yang positif terhadap suku bunga dan sifatnya permanen. Berdasarkan variance decomposition, maka terlihat bahwa suku bunga sangat kecil kontribusinya terhadap variabilitas output gap yaitu sekitar $0-4,6 \%$. Suku bunga memiliki kemampuan untuk menjelaskan variabilitas inflasi sekitar $14 \%$ sampai dengan $32 \%$. Jadi, dapat disimpulkan bahwa adanya kejutan inflasi ternyata direspon secara cepat oleh suku bunga dibandingkan dengan kejutan output gap.

\section{PUSTAKA ACUAN}

Dornbusch, Rudiger, et.al. 2004. Macroeconomics. New York: Mc Graw Hill.

Engle, Robert F. and Clive W.J. Granger. 1987. Cointegration and Error Correction: Representation, Estimation and Testing. Econometrica, Vol.55, N0.2, pp. 251-279

Gujarati, Damodar. 2009. Basic Econometrics. New York: McGraw Hill. Howells, Peter. and Bain, Keith. 1998. The Economics of Money, Banking and Finance: a European Text. England: Addison Wesley Longman.

Insukindro. 1992. Pendekatan Kointegrasi dalam Analisis Ekonomi: Studi Kasus Permintaan Deposito dalam Valuta Asing di Indonesia. Jurnal Ekonomi Indonesia, Vol.1, No.2, pp. 259-270.

Mankiw, N. Gregory. 2009. Macroeconomic. New York: Worth Publisher. 
Mishkin, Frederic S. 2009. The Economic of Money, Banking and Financial Market. Boston: Addison Wesley Longman.

Montoro, Carlos. 2007. Monetary Policy Committees and interest rate Smoothing. Centre for Economic Performance Discussion Paper No. 780. London School of Economics and Political Science.

Sack, Brian and Volker Wieland. 1999. Interest-Rate Smoothing and Optimal Monetary Policy: a Review of Recent Empirical Evidence. Finance and Economic Discussion Series, 39, Board of Governors of the Federal Reserve System.

Solikin. 2002. Kurva Phillips dan Perubahan Struktural di Indonesia. Kuliah Umum, 20 Desember, Magister Sains UGM.

Warjiyo, Perry. dan Doddy Zulverdi. 1998. Penggunaan Suku Bunga sebagai Sasaran Operasional Kebijakan Moneter di Indonesia. Buletin Ekonomi Moneter dan Perbankan. 